\title{
A TRILHA PARA A DIVULGAÇÃO INTERNACIONAL DA CIRURGIA BRASILEIRA
}

\section{Luiz Francisco Poli de Figueiredo, TCBC-SP*}

Após oito anos como Diretora de Publicações, a Dra. Merisa Garrido, deixa a Revista do Colégio Brasileiro de Cirurgiões pronta para ingressar em uma nova e promissora fase. Em seu editorial de despedida, cita "tudo foi feito seguindo a trilha e o exemplo que me deixou o meu antecessor - o ilustre ECBC Marcos Moraes - e espero que tenha continuidade".

Por ocasião do XXIII Congresso Brasileiro de Cirurgia, em julho de 1999, em reunião com Membros do Conselho Editorial e Redatorial, a Dra. Merisa traçou a trilha que permitirá, em curto espaço de tempo, que a Revista do CBC amplie seus horizontes, divulgando a ciência e a arte da cirurgia brasileira para a comunidade científica internacional.

$\mathrm{O}$ resultado desta reunião bem como as sugestões dos presentes ou de seus representantes encontram-se publicados no Boletim Informativo do CBC, Ano XXX - julho/setembro - 1999 - № 105 - pág. 10-12. Algumas já estão sendo empregadas, e outras como "Instruções aos Colaboradores" serão divulgadas na Revista do CBC, edição $n^{\circ}$ 2/2000 (março/abril). Deve ser ressaltado que os Membros do Conselho Redatorial já foram comunicados das novas mudanças, que passarão a ser exigidas para os trabalhos científicos enviados para publicação a partir de 01 de junho de 2000.

Consta da atual página de Instruções aos Colaboradores que a Revista do CBC "se propõe à divulgação de artigos concernentes à cirurgia ou especialidades correlatas, que contribuam para o seu ensino, desenvolvimento e integração nacional". Nossa Revista já satisfaz plenamente estes objetivos. Para que possamos contribuir com a comunidade científica internacional para o progresso da cirurgia, diversas medidas devem ser imediatamente adotadas, e fazem parte desta trilha.

Neste número já estão incluídas as "Instruções aos Colaboradores" que seguem as diretrizes estabelecidas pela chamada Convenção de Vancouver, publicada em 1997. Acreditamos que o principal fator de impacto induzido por estas novas diretrizes é o (resumo/abstract) estruturado. A melhoria do (resumo/abstract) será diretamente responsável pelo aprimoramento da qualidade dos nossos artigos e pela divulgação internacional da cirurgia brasileira. $O$ resumo estruturado exige que o autor apresente sistematicamente o objetivo do estudo, o protocolo da pesquisa básica, o cenário clínico, os participantes, as intervenções realizadas, os resultados principais e as conclusões. Resumo de artigos de revisão deve conter o objetivo, as fontes de dados, os métodos de seleção dos estudos, a obtenção e síntese dos dados, e as conclusões.

O resumo deve fornecer ao leitor os elementos que lhe permitam decidir sobre a conveniência ou não de consultar o texto completo. Estudos recentes sobre o uso do MEDLINE sugerem que decisões clínicas têm sido tomadas baseadas nos resumos estruturados, sem a leitura do trabalho completo. As conclusões no resumo estruturado devem estar restritas às evidências do artigo em si. O resumo não deve conter especulações sobre possíveis aplicações clínicas. Deve ser dada importância semelhante aos achados positivos e negativos e às variáveis sem diferença estatística, desde que relevantes. Por outro lado, o resumo pode conter imperfeições, tendenciosidades e omitir dados fundamentais. Portanto, deve ser grande o esforço dos Membros do Conselho Editorial e Redatorial para que os resumos e abstracts da Revista do CBC primem pela alta qualidade e correspondam às expectativas dos leitores do Brasil e de outros países.

Estas medidas facilitarão o ingresso da Revista do CBC no SciELO (The Scientific Eletronic Library Online), outra meta estabelecida na reunião da Revista em julho de 1999. O SciELO é uma biblioteca eletrônica virtual na qual estão incluídas diversas Revistas científicas brasileiras, projeto da FAPESP em parceria com a BIREME. Este projeto desenvolve uma metodologia comum para a preparação, divulgação e avaliação da literatura científica em formato eletrônico. Ingressando no SciELO, os resumos estruturados ou mesmo o artigo completo serão disponibilizados para todo o mundo pela PubMed-MEDLINE, facilitando a citação dos nossos trabalhos e aumentando a integração com a comunidade científica internacional.

É necessário um grande empenho de todos para que a nossa Revista faça por merecer a prioridade de contribuições de diversos setores da cirurgia brasileira que pouco tem utilizado a Revista do CBC para divulgar o conhecimento por eles gerado. O Colégio Brasileiro de Cirurgiões é uma instituição poderosa e sua Revista deve refletir a qualidade de nossa cirurgia. Seguindo exemplos como o proporcionado pela Dra. Merisa Garrido, em curto espaço de tempo nossos objetivos serão naturalmente atingidos.

* Professor Associado, Departamento de Cirurgia da UNIFESP/EPM e Departamento de Cardiopneumologia, InCor, FM-USP. 